\title{
Does the currency regime shape unhedged cur- rency exposure?
}

\author{
Ila Patnaik, Ajay Shah
}

Working Paper 2008-50

April 2008

NIPFP-DEA Research Program on Capital Flows and their Consequences National Institute of Public Finance and Policy New Delhi http://www.nipfp.org.in/nipfp-dea-program/index.html 


\title{
Does the currency regime shape unhedged currency exposure?
}

\author{
Ila Patnaik* Ajay Shah
}

May 10, 2008

\begin{abstract}
This paper examines how unhedged currency exposure of firms varies with changes in currency flexibility. A sequence of four time-periods with alternating high and low currency volatility in India provides a natural experiment in which changes in currency exposure of a panel of firms is measured, and the moral hazard versus incomplete markets hypotheses tested. We find that firms carried higher currency exposure in periods when the currency was less flexible. We also find homogeneity of views, where firms set themselves up to benefit from a rupee appreciation, in the later two periods. Our results support the moral hazard hypothesis that low currency flexibility encourages firms to hold unhedged exposure in response to implicit government guarantees.
\end{abstract}

JEL Codes: F31, G32.

Keywords: currency regime, currency exposure of firms, moral hazard, one-way bets on exchange rates.

${ }^{*}$ Corresponding author. Email: ilapatnaik@gmail.com, Fax +91-11-26852548. This work is part of the NIPFP-DEA Research Program on Capital Flows and their Consequences. We are grateful to participants of the 1st research meeting of this program, and particularly the discussant Barry Eichengreen, for insightful comments which greatly improved the work. 


\section{Contents}

1 Introduction $\quad 3$

2 Data and methodology $\quad 5$

2.1 Structural breaks in currency flexibility . . . . . . . . . . . . . . . 5

2.2 The firm-level data set . . . . . . . . . . . . . . . . . . 8

2.3 Measuring currency exposure ................... . . . 9

3 Firm level evidence $\quad 11$

3.1 Changes in currency exposure ................... 11

3.2 Direction of exposure . . . . . . . . . . . . . . . . . . . 14

4 Conclusions $\quad 16$ 


\section{Introduction}

The choice of exchange rate regime has seen renewed debate among policy makers and researchers in recent times (Ghosh et al., 2002; Ize and Yeyati, 2003; Fischer, 2006). One possible rationale for currency pegging or the "fear of floating" in emerging markets is the financial fragility of banks and firms. It is argued that incomplete financial markets in emerging economies limit the capacity of firms to hedge their currency exposure, and that the exposure of firms leads central banks to avoid currency flexibility (Calvo and Reinhart, 2002; Levy-Yeyati and Sturzenegger, 2003).

A second view identifies the moral hazard created by currency pegs as a source of balance sheet mismatches (Eichengreen and Hausmann, 1999). When the central bank pegs the exchange rate, low volatility against a target currency gives firms an implicit guarantee against short term movements of the exchange rate. Burnside et al. (2001) and Schneider and Tornell (2004) show that carrying unhedged currency exposure is an optimal response on the part of firms enjoying government guarantees.

A recent theoretical literature (e.g. Chang and Velasco (2005)) suggests that the relationship may hold both ways. A central bank chooses the exchange rate regime depending on the extent of currency mismatches. The fear of floating may give rise to a peg. In turn, the optimal response of firms to the implicit guarantee offered by the central bank is to carry unhedged currency exposure. These two processes could reinforce each other in an equilibrium with unhedged firms and pegged exchange rates.

Over the past decade, an extensive literature has used macroeconomic data to expore the relationship between exchange rate regimes and currency mismatches. ${ }^{1}$ This literature is based on the argument that pegging the currency is more credible in the short run. If firms are taking higher risks in response to a peg, it should result in greater short term foreign currency denominated credit. However, few studies find strong empirical support for the hypothesis (Eichengreen and Hausmann, 1999).

Empirical studies using firm level data find some support for the moral hazard hypothesis for Latin America, Mexico and East Asia. Kamil (2006) and Martinez and Werner (2002) find that moving to more flexible regimes reduced currency mismatches on balance sheets of firms. Parsley and Popper (2006) find that firms in East Asia were less hedged under pegged exchange rates. However, with cross country evidence, it is difficult to distinguish between the incomplete markets and the moral hazard hypotheses.

This paper complements the existing literature by explicitly examining the incomplete market versus the moral hazard view in the context of volatility changes under a pegged currency regime. India provides a unique natural experiment, where we can study the response of a set of firms placed under alternating high and low volatility phases of a pegged exchange rate regime. The rupee has been pegged to the USD in the period 1993-2006,

\footnotetext{
${ }^{1}$ For a review of this literature see Luca and Zhang (2006).
} 
but four distinct periods of significantly different currency volatility can be identified. The first period beginning in 1993 when the rupee moved away from an administered exchange rate was a period of low currency volatility. This was followed by a period of high volatility during the Asian crisis. The third period identified witnessed low volatility, followed by the fourth of high volatility. The extent of market completeness, in terms of capital controls or access to currency derivatives, did not fundamentally change. The empirical strategy of the paper derives strength from the fact that a stable set of firms, where a sound metric of currency exposure is obtained, are observed through three significant changes in currency flexibility.

Under this natural experiment, the incomplete markets and moral hazard hypotheses have different predictions. If firms are unable to hedge their foreign exchange exposure risk, owing to incomplete markets, higher currency volatility should not affect the currency exposure of firms. If the incomplete market hypothesis were true, we would find that whether the currency volatility was high or low, unhedged currency exposure of firms remains unchanged. If the moral hazard hypothesis were true, and firms carry currency risk in response to the flexibility of the currency, we should find that periods of low volatility have high unhedged currency risk, and vice versa.

Our results strongly support the moral hazard hypothesis. We find that in Period 1, when there was negligible currency volatility, firms had large exposures. This gave way to the high currency volatility of Period 2: we find that currency exposure of firms became very low. In Period 3, currency volatility was low and firms responded with increased unhedged exposure. Period 4 witnessed an increase in volatility and a reduction in unhedged currency exposure.

In addition to questions about the magnitude of unhedged currency exposure, we also ask questions about the direction of exposure. Was there homogeneity in the direction of the currency exposure of firms? Did firms see a one-way bet on the exchange rate? Our results suggest that in periods 3 and 4 , firms as a whole were betting on currency appreciation. These were periods where the central bank was buying foreign currencies at a high rate in an attempt to undervalue the rupee. Period 4 is a particularly interesting case: while currency volatility had risen, the government continued to sell rupees on the currency market at a high rate. Higher volatility in Period 4 was associated with a reduction in unhedged currency exposure of firms, but we find that firms, as a whole, had a highly statistically significant bet on appreciation.

In summary, our results suggest that in a natural experiment where market completeness was unchanged, the currency exposure of firms responded powerfully to the implicit guarantees made by the government in the currency regime. When the government tightly managed the exchange rate, firms carried substantial currency exposure. When there was greater currency flexibility, firms switched to lower unhedged exposures.

The remainder of this paper is divided into three sections. Section 2 describes the firm level data set, the methodology for the identification of structural breaks in currency flexibility 
and measurement of currency exposure of firms. Section 3 discusses the impact of changes in currency flexibility on the magnitude and direction of currency exposure of firms. Section 4 concludes.

\section{Data and methodology}

This section describes the data and methodology used this study. The first part explains the structural breaks methodology for the identification of episodes of currency volatility in India. The second part describes the firm level data set. The third outlines the methodology used for measuring currency exposure.

\subsection{Structural breaks in currency flexibility}

The INR currency regime has been de facto pegged to the USD over the full period. The extent of pegging has varied significantly through this period. There have been multimonth periods where the INR/USD exchange rate was fixed, and there have been periods where the volatility of the INR/USD was much higher.

The Reserve Bank of India has not announced any change in the currency regime since the move to a "market determined rate" in 1993. The rupee has been classified as a managed float by the IMF AREARS (Annual Report on Exchange Agreements and Exchange Restrictions). Calvo and Reinhart (2002), Reinhart and Rogoff (2004) and Patnaik (2007) present evidence that the rupee was a de facto peg to the USD.

Due to domestic and external compulsions, rupee volatility varied sharply during this period. ${ }^{2}$ Hence, within the broad framework of a INR/USD pegged exchange rate, there was important variation of INR/USD volatility in sub-periods. We use the Bai and Perron (2003) algorithm as implemented by Zeileis et al. (2005) to identify structural breaks in exchange rate volatility. ${ }^{3}$

Figure 1 shows the time-series of squared weekly returns on the INR/USD exchange rate, with the break dates isolated by the Bai and Perron (2003) algorithm superposed. The three break dates identify four distinct periods:

Period 1: 2 April 1993 to 17 February 1995 This was a period of low volatility. For most of this period, the rupee stood at Rs.31.37 per dollar.

\footnotetext{
${ }^{2}$ The evolution of the currency regime reflected compulsions rooted in monetary policy and the evolution of capital controls (Patnaik, 2005; Shah and Patnaik, 2007). These influenced the Reserve Bank's decision to permit higher currency volatility in certain periods.

${ }^{3}$ To estimate structural breaks, the exchange-rate time-series is re-expressed as a time-series of weekly returns. The Bai and Perron (2003) algorithm is applied to the OLS regression $\log r^{2}=a_{0}$. This yields a set of break dates.
} 


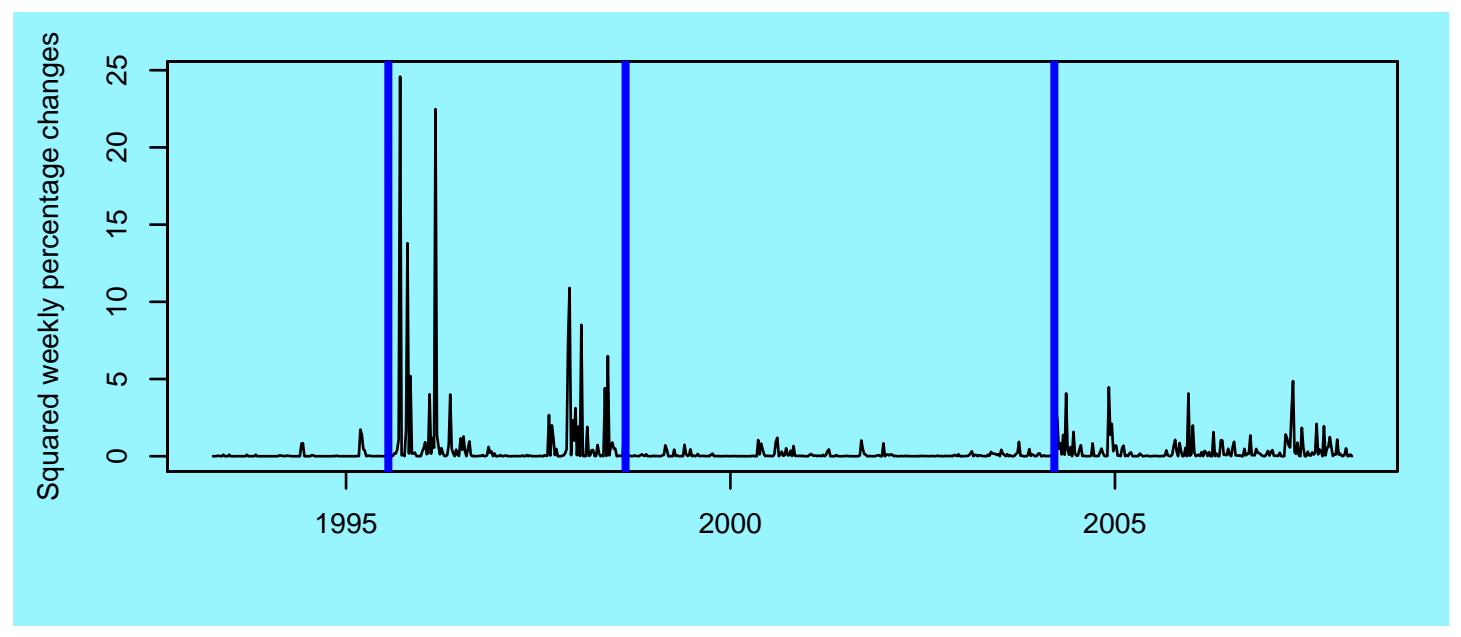

Figure 1: Squared weekly returns on the INR/USD exchange rate and structural break dates.

\begin{tabular}{llrrr}
\hline & & \multicolumn{2}{c}{ INR/USD } & \multicolumn{2}{c}{ Reserves addition (Bln. USD) } \\
\cline { 4 - 5 } & Dates & Weekly vol. & Overall & Per year \\
\hline 1 & $1993-04-01-1995-02-17$ & 0.16 & 13.03 & 6.93 \\
2 & $1995-02-17-1998-08-21$ & 0.93 & 4.86 & 1.39 \\
3 & $1998-08-21-2004-03-19$ & 0.29 & 82.64 & 14.81 \\
4 & $2004-03-19-2007-02-12$ & 0.61 & 79.76 & 27.50 \\
\hline
\end{tabular}

Table 1: The four periods

Period 2: 18 February 1995 to 21 August 1998 This period included the Asian crisis, and there was a sharp increase in currency volatility.

Period 3: 22 August 1998 to 19 March 2004 This was a period of tight pegging, with low volatility and some appreciation.

Period 4: 20 March 2004 to 12 February 2007 In this period, there was greater currency flexibility. However, currency flexibility was lower than in Period 2.

Table 1 shows the currency volatility of the INR/USD exchange rate across these four periods. Currency volatility was highly heterogeneous across the four periods. It moved from $0.16 \%$ per week in Period 1 to a nearly six-times higher level of $0.93 \%$ per week in Period 2. In Period 3 it dropped to one-third (to 0.29) and then roughly doubled (to 0.61) in period 4 . These were large changes in currency volatility.

Over the full period, India had restrictions on the capital account. Financial derivatives were not well developed and there were restrictions on participation in these markets. Financial markets grew and developed over this period without major setbacks, policy 
The vertical lines demarcate the four periods based on structural breaks in the currency regime.

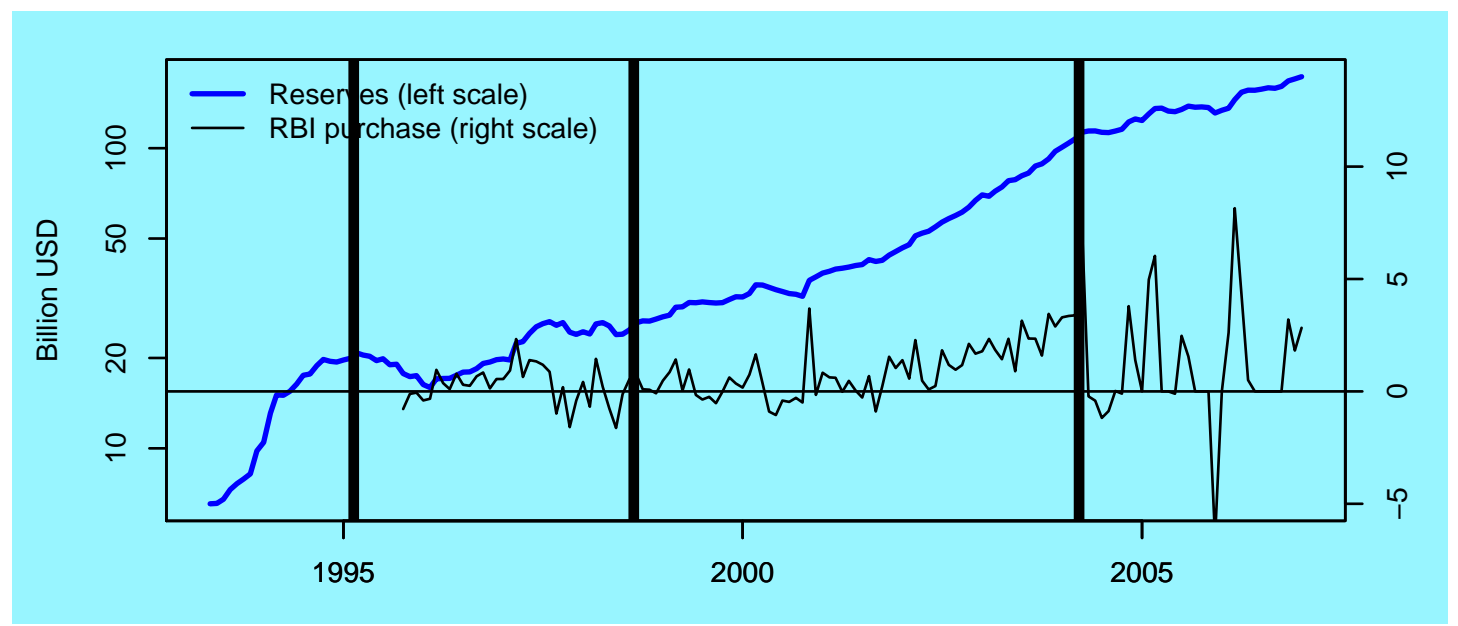

Figure 2: Foreign currency purchases by RBI, and reserves

reversals or structural breaks. ${ }^{4}$ From the viewpoint of experimental design, there was a broadly consistent policy environment. Through the entire period, no announcements were made about the nature of the currency regime or currency volatility. Firms had to look at data on exchange rates and form their own assessment about the outlook for currency risk.

The dates of structural break identified above have interesting economic interpretations when juxtaposed against the foreign currency reserves and purchases of the Reserve Bank of India (RBI). Figure 2 shows the monthly time-series of foreign currency reserves and of net purchase of foreign exchange by RBI. The three vertical lines demarcate the four periods that we examine.

For Period 1, the rupee had just shifted into the new 'market determined exchange rate'. Data for net purchase has not been released, and there was a small buildup of reserves. Within Period 2, the period of the Asian crisis, a small decline in reserves took place and the currency moved sharply. In Period 3, there was sustained currency intervention almost entirely on one side of the market, and reserves rose dramatically. This may have been a period when economic agents felt that the currency was likely to appreciate. Finally, in Period 4, while intervention data shows a less sustained pattern, the presence of enormous reserves would suggest to economic agents that a sudden depreciation was unlikely.

As is visible in Table 1, the characteristics of the four periods can be summarised in two dimensions. In Periods 1 and 3, currency volatility was low. In Periods 3 and 4, the pace of reserves accretion was high.

\footnotetext{
${ }^{4}$ See Thomas (2006) for a comprehensive description of the evolution of financial markets in this period.
} 
The CMIE Cospi is a set of roughly 2,500 listed firms in India which trade on atleast $66 \%$ of trading days. It constitutes the universe of Indian listed firms, for all practical purposes. The 100 firms in Nifty and Nifty Junior, which are used in this paper, account for an economically significant part of this universe.

\begin{tabular}{lrr} 
& \multicolumn{2}{c}{ (Trillion Rupees) } \\
\hline Set & Market value & Value added \\
\hline CMIE Cospi (2500 firms) & 35.3 & 4.74 \\
Nifty (50 firms) & 19.6 & 2.33 \\
Nifty Junior (50 firms) & 3.3 & 0.71 \\
\hline Fraction accounted for by 100 firms & 0.65 & 0.64 \\
\hline
\end{tabular}

Table 2: Weight of 100 sample firms in overall equity market and value added

\subsection{The firm-level data set}

Firm-level empirical work in developing countries, where financial markets are not welldeveloped, often uses balance sheet data to study currency mismatches (Kamil, 2006; Cowan et al., 2004; Martinez and Werner, 2002). Balance sheet data suffers from the obvious limitation that it does not show off-balance sheet information. Currency exposures observed in balance sheet data may be misleading if the exposure is hedged off-balance sheet; conversely, firms seeking to speculate on exchange rate changes may use off-balance sheet exposures to obtain currency exposure.

Compared with many developing countries, India has the advantage of high participation in financial markets and active speculative price discovery on the stock market. As an example, the 3rd and 5th biggest exchanges of the world, measured by the number of transactions per year, are found in India. This makes an exposure metric derived from stock prices relatively informative.

We construct a data set of 100 most liquid stocks on Indian stock exchanges. These are the firms that belong to the 'NSE-50' (Nifty) and 'Nifty Junior' stock market indexes. The prime rationale for choosing these 100 firms lies in the informativeness of their stock price processes, given the high level of stock market liquidity. In terms of market turnover, these 100 firms account for $58 \%$ of the turnover of the spot market. Index derivatives and individual-stock derivatives on these 100 stocks account for $92 \%$ of total equity derivatives turnover. ${ }^{5}$

\footnotetext{
${ }^{5}$ The methodology for construction of Nifty and Nifty Junior (Shah and Thomas, 1998) is based on computing the impact cost when placing program trades to buy or sell the entire index as a portfolio, into four 'snapshots' of the limit order book every day. The biggest firms of the country are selected into these two indexes, while ensuring that the overall impact cost of index program trades remains low. As an example, in 2006, the average impact cost for doing a Rs.5 million program trade on Nifty was $0.08 \%$ and the impact cost for doing a Rs.2.5 million program trade on Nifty Junior was $0.16 \%$. These transactions costs are comparable with program trades on indexes in industrial countries, and underline the high quality of stock market liquidity and informativeness of the stock prices in the dataset.
} 
In addition, Table 2 shows that these 100 firms account for roughly two-thirds of the value added and market value of non-trivial listed firms in India. The value added by these 100 firms amounts to roughly $10 \%$ of India's GDP. Hence, this dataset of 100 firms is simultaneously a set of firms where risk measurement based on stock price sensitivity is meaningful, and a set of firms which is representive of the currency exposure of Indian firms at large.

\subsection{Measuring currency exposure}

We measure unhedged currency exposure in the tradition of Adler and Dumas (1984). We build on the work of Dominguez and Tesar (2006); Parsley and Popper (2006); Dahlquist and Robertsson (2001); Jorion (1990); Bodnar and Wong (2000) and measure the change in the stock price of a company in response to a change in the exchange rate. To measure the unhedged currency exposure of firms we utilize an 'augmented market model':

$$
r_{j}=\alpha_{j}+\beta_{1 j} r_{M 1}+\beta_{2 j} r_{M 2}+\epsilon
$$

The model relates firm returns $r_{j}$ to market index movements $r_{M 1}$ and currency fluctuations $r_{M 2}$. The coefficient $\beta_{2 j}$ measures the sensitivity of the valuation of firm $j$ to changes in the exchange rate. If an exporting firm is unhedged and gains when there is a currency depreciation, it would have $\beta_{2 j}>0$.

In an efficient market, market model parameters reflect the efforts of speculative markets at putting together all aspects of currency exposure of the firm. If a firm sells a product which is priced through import parity, stock market speculators who form a judgment about future profits of the firm will embed currency fluctuations into the stock price process, even when it does not appear in balance sheet disclosures about currency exposure.

We follow Parsley and Popper (2006) and Dahlquist and Robertsson (2001) in focusing on a bilateral exchange rate, the INR/USD, in contrast to other studies such as Dominguez and Tesar (2006) who have used trade-weighted exchange rates to measure currency exposure. A focus on the USD in gauging the currency exposure of firms in India is consistent with (a) the fact that the INR is a de facto peg to the USD; (b) key trade partners such as the US, China, Hong Kong and UAE are all pegged to the USD and (c) considerable trade invoicing takes place in USD. ${ }^{6}$

The stock price of a firm at any point of time takes into account all information available at that point. The stock market price is likely to respond only to unanticipated changes in the exchange rate (Doukas et al., 2001). To measure the response of the stock market

\footnotetext{
${ }^{6}$ In order to explore the significance of exposures other than the USD, augmented market models were estimated for the biggest 20 companies by market capitalisation, where Euro, Pound and Yen exposures were measured in addition to the USD. These were not significant.
} 
to innovations, rather than levels in the exchange rate, we examine the time series characteristics of the INR/USD exchange rate. We find that the time-series of the INR/USD exchange rate often deviates from a random walk. ARMA identification based on the Akaike Information Criterion suggests that $r_{M 2}$ often has an AR time-series structure. ${ }^{7}$ This suggests shifting from raw currency market returns, $r_{M 2}$, to ARMA innovations, $e_{t}$. This is done separately in each of the four periods to model and utilise the nature of the currency process prevalent in the period under examination.

The full impact of a currency innovation takes place over several time-periods, which requires introducing a set of lags into the estimating equation. Tests with a series of individual stocks suggested that the impact of a shock was fully absorbed in no more than 4 lags of weekly data. This implies the model specification:

$$
r_{j t}=\alpha_{j}+\beta_{1 j} r_{M 1, t}+\sum_{i=0}^{4} a_{i j} e_{t-i}+\epsilon_{t}
$$

Under this specification, an innovation $e_{t}$ on the currency market has an impact on the stock price in week $t$ and in the following 4 weeks.

Under model 2, currency exposure is embedded in the vector of $a_{i j}$ coefficients; it is no longer a simple scalar $\beta_{2 j}$ as was the case under model 1 . The metric of currency exposure of the firm that we utilise is $\bar{\beta}_{2 j}=\sum a_{i}$. Inference procedures for $\bar{\beta}_{2 j}$ are based on a heteroscedasticity- and autocorrelation-consistent covariance matrix (Andrews and Monahan, 1992) for the OLS estimates of equation 2. This gives us an estimate $\sigma_{2 j}$, of the dispersion of the distribution of $\bar{\beta}_{2 j} .{ }^{8}$ Table 3 shows one example of this estimation strategy.

Through this process, for each firm $j$, estimates for currency exposure $\bar{\beta}_{2 j}$ and the standard deviation of the estimate $\sigma_{2 j}$ are obtained.

The direction of unhedged currency exposure may differ across firms. Some firms may benefit from an appreciation $\left(\bar{\beta}_{2 j}<0\right)$, while others may benefit from a depreciation

\footnotetext{
${ }^{7}$ Based on the AIC, the overall weekly returns time-series of the INR/USD exchange rate appears to be an $\operatorname{AR}(2)$ process with the following parameters:

\begin{tabular}{lrr}
\hline & Coefficient & Std.Err. \\
\hline Intercept & 0.0566 & 0.0266 \\
AR1 & 0.1181 & 0.0379 \\
AR2 & 0.0610 & 0.0379
\end{tabular}

However, the time-series process of the currency varies significantly across the four periods which were identified when analysing the currency regime. In the first period, INR/USD returns were AR(3) with pronounced mean reversion. In the second period, it was an $\mathrm{AR}(1)$ with a positive coefficient. In the third period, it was an $\mathrm{AR}(10)$. In the fourth period, there was no AR structure.

${ }^{8}$ Let $\beta$ be the OLS estimate. We define $w=[0,0,1,1,1,1,1]$. Our exposure metric $\bar{\beta}_{2 j}=\sum a_{i}=w^{\prime} \beta$. We obtain $\Sigma$, a consistent estimate of $\operatorname{Var}(\beta)$. This is used to compute $\operatorname{Var}\left(\bar{\beta}_{2 j}\right)=w^{\prime} \Sigma w$.
} 
This table shows an example of estimation of equation 2 and hence $\bar{\beta}_{2 j}$ for one firm: Satyam Computer Services, in period 4. This is an export oriented software services firm. The typical exposure expected of an incompletely hedged exporting firm is $a_{i j}>0$ where positive stock market returns take place in response to a currency depreciation.

In the case of Satyam, there is a contemporaneous response of 1.0339 , which is statistically significant. In other words, a currency innovation of 1\% induces stock market returns of $1.0339 \%$ in the same week. However, the currency innovation of week 0 continues to trickle into the stock price over the next four weeks, with positive coefficients for $e_{1}, e_{2}, e_{3}$ and $e_{4}$. The five $a_{i j}$ estimates add up to a total impact of 2.4389 .

\begin{tabular}{rrrrr}
\hline & Estimate & Std. Error & $\mathrm{t}$ value & $\operatorname{Pr}(>|\mathrm{t}|)$ \\
\hline (Intercept) & 0.2471 & 0.2750 & 0.90 & 0.3708 \\
$r_{M 1}$ & 0.9194 & 0.0960 & 9.57 & 0.0000 \\
$e_{0}$ & 1.0339 & 0.5026 & 2.06 & 0.0420 \\
$e_{1}$ & 0.2789 & 0.4568 & 0.61 & 0.5428 \\
$e_{2}$ & 0.1933 & 0.4688 & 0.41 & 0.6809 \\
$e_{3}$ & 0.6478 & 0.4494 & 1.44 & 0.1523 \\
$e_{4}$ & 0.2851 & 0.4390 & 0.65 & 0.5173 \\
$R^{2}$ & 0.4697 & & & \\
$\bar{\beta}_{2 j}$ & 2.4389 & 0.8837 & 2.76 & \\
\hline
\end{tabular}

Table 3: Measurement of currency exposure at the firm level: An example

$\left(\bar{\beta}_{2 j}>0\right)$. To focus on currency exposure, regardless of the sign, we use $\left|\bar{\beta}_{2 j}\right|$ as the metric of unhedged currency exposure.

The inference procedure for the average, $\overline{\left|\beta_{2}\right|}=E\left(\left|\bar{\beta}_{2 j}\right|\right)$, uses a simulation-based strategy. In each simulation, one draw is made from the distribution of $\bar{\beta}_{2 j}$ for each firm, and $\overline{\left|\beta_{2}\right|}$ is computed using these values. This is repeated 5000 times, which yields 5000 draws from the distribution of $\overline{\left|\beta_{2}\right|}$. Summary statistics and kernel density plots are reported using these draws.

\section{$3 \quad$ Firm level evidence}

This section describes our results. The first part discusses variation in the level of currency exposure, regardless of the direction. The second examines the direction of currency exposure of firms.

\subsection{Changes in currency exposure}

Table 4 shows summary statistics about the cross-sectional dispersion of $\left|\bar{\beta}_{2 j}\right|$ in each period. 
This table shows summary statistics about the $\left|\bar{\beta}_{2 j}\right|$ values obtained across firms in the four periods.

\begin{tabular}{lrrrr}
\hline Period & Q1 & Median & Mean & Q3 \\
\hline 1 & 3.04 & 5.83 & 9.03 & 10.82 \\
2 & 0.34 & 0.58 & 0.76 & 0.93 \\
3 & 0.89 & 1.80 & 2.29 & 3.24 \\
4 & 0.34 & 0.86 & 1.14 & 1.60 \\
\hline
\end{tabular}

Table 4: Summary statistics about the cross-section of $\left|\bar{\beta}_{2 j}\right|$ in 4 periods

\begin{tabular}{lrr}
\hline Period & $\overline{\left|\beta_{2}\right|}$ & Std. Devn. \\
\hline 1 & 12.596 & 1.198 \\
2 & 1.041 & 0.095 \\
3 & 3.447 & 0.258 \\
4 & 1.492 & 0.099 \\
\hline
\end{tabular}

Table 5: $\overline{\left|\beta_{2}\right|}$ estimates, along with simulation-based inference

In Period 1, where currency flexibility was very limited, the exposure of firms was considerable. The 25 th percentile was 3.04 and the 75 th percentile was 10.82 .

In Period 2, when the highest currency volatility was observed, the exposure of firms fell dramatically. The 25 th percentile dropped to 0.34 and the 75 th percentile dropped to 0.93 .

In Period 3, where currency flexibility once again dropped, though not all the way to the levels of period 1 , the 25 th percentile rose to 0.89 and the 75 th percentile climbed to 3.24.

Finally, in Period 4, where greater currency volatility came about (though not up to the levels of Period 2), currency risk dropped sharply, with a 25th percentile of 0.34 and a 75 th percentile of 1.60 .

Currency volatility in the four periods took the values of : $0.16,0.93,0.29,0.61$. The median exposure of firms responded in ways which are consistent with a moral hazard hypothesis, with values of: $5.83,0.58,1.80,0.86$.

The simulation-based inference strategy described in Section 2.3 gives us $\overline{\left|\beta_{2}\right|}$, the mean of $\left|\bar{\beta}_{2 j}\right|$ across firms along with an estimate of its sampling variation. These results are shown in Table 5.

For all the transitions from one period to the next, the change in the mean exposure is highly significant. As an example, the 95\% confidence interval in Period 3 runs from 2.94 to 3.95 , while the $95 \%$ confidence interval in Period 4 runs from 1.299 to 1.686. We infer that at a high level of significance, $\overline{\left|\beta_{2}\right|}$ was lower in Period 4 when compared with Period 3 .

Figure 3 visually compares kernel density plots for the distribution of $\overline{\left|\beta_{2}\right|}$ in the four 

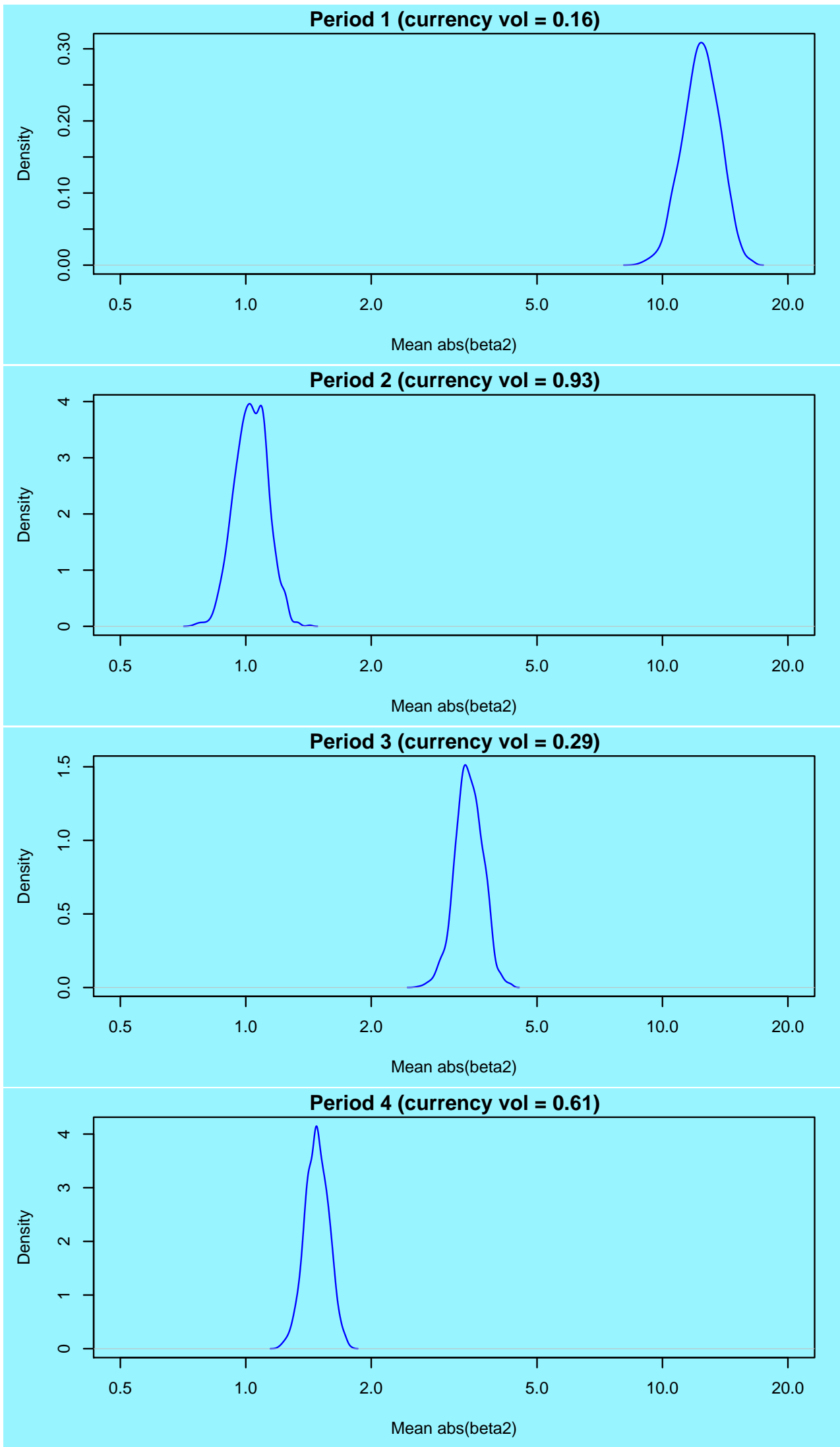

Figure 3: Distribution of $\overline{\left|\beta_{2}\right|}$ in the four periods 
periods. The lack of overlap of consecutive distributions supports the hypothesis that each time currency volatility changed, the exposure of firms changed. In comparing Period 2 and Period 4, while the currency volatility was different (0.93 vs. 0.61), the distributions of $\overline{\left|\beta_{2}\right|}$ overlap significantly; we cannot reject the null of no-difference in $\overline{\left|\beta_{2}\right|}$. Apart from this case, pairwise comparisons for all the four periods reveal clearly distinct distributions for $\overline{\left|\beta_{2}\right|}$.

In summary, we find that when currency volatility switched from a low level in Period 1 to a high level in Period 2, the currency exposure of firms dropped sharply. When currency volatility dropped again in Period 3, the exposure of firms went up. Finally, when currency volatility rose again in Period 4, the exposure of firms went down.

This evidence represents one key finding of this paper: that changes in currency flexibility were associated with significant changes of the currency exposure of firms. Markets were developed enough to give firms the instruments through which they were able to raise or lower their currency exposure in response to changes in currency flexibility. The switch from carrying low to high unhedged currency exposure was a response to lower currency volatility. This result supports the moral hazard hypothesis on the unhedged currency exposure of firms.

\subsection{Direction of exposure}

Our results so far have focused on summarising the cross-sectional distribution of $\left|\bar{\beta}_{2 j}\right|$ : the sensitivity of stock returns to currency returns, without concern for the direction of firm exposure. However, pegged exchange rates are known to sometimes induce one-way bets on the exchange rate. In this case, the speculative views of firms could converge.

When the central bank consistently buys dollars to prevent appreciation and accumulates large foreign exchange reserves, economic agents are likely to infer (a) that INR appreciation is likely and (b) that a large sudden depreciation is unlikely. Conversely, at a time when the central bank is defending the currency with continual sale of reserves, economic agents are likely to infer that (a) that INR depreciation is likely and (b) a large sudden depreciation could occur.

Did firms feel that the currency was sometimes a one-way bet, and choose similar $\bar{\beta}_{2 j}$ values in a period? In order to investigate this, we explore the cross-section of $\bar{\beta}_{2 j}$ seen in the four periods. We summarise this using the mean of $\bar{\beta}_{2 j}$ : the currency exposure of the overall sample, even after positive and negative exposures are allowed to cancel out. Thus, $\beta_{2}=E\left(\bar{\beta}_{2 j}\right)$ is a measure of the overall currency exposure of the firms of India, as distinct from $\overline{\left|\beta_{2}\right|}$, which measured whether firms had currency exposure (regardless of direction). Assuming that $\bar{\beta}_{2 j}$ estimates across $N$ firms are independent, our inference procedures are based on $\operatorname{Var}\left(\beta_{2}\right)=\frac{1}{N^{2}} \sum \sigma_{2 j}^{2}$.

Table 6 shows summary statistics of the $\bar{\beta}_{2 j}$ values obtained, without shifting to absolute 
This table shows the cross-sectional variation of $\bar{\beta}_{2 j}$ in the four periods.

\begin{tabular}{lrrrr}
\hline Period & Q1 & Median & Mean & Q3 \\
\hline 1 & -4.765 & 2.567 & 2.635 & 7.729 \\
2 & -0.678 & -0.354 & -0.200 & 0.250 \\
3 & -2.818 & -0.688 & -0.835 & 0.961 \\
4 & -1.542 & -0.378 & -0.673 & 0.216 \\
\hline
\end{tabular}

Table 6: Cross-section variation of $\bar{\beta}_{2 j}$

\begin{tabular}{lrr}
\hline Period & $\bar{\beta}_{2}$ & Std. Devn. \\
\hline 1 & 2.6325 & 1.609 \\
2 & -0.2002 & 0.125 \\
3 & -0.8346 & 0.367 \\
4 & -0.6733 & 0.122 \\
\hline
\end{tabular}

Table 7: $\bar{\beta}_{2}$ estimates

values as was done earlier.

In Period 1, the mean and median values were positive and roughly $2.5 \%$. In other words, on average, firms stood to benefit by $2.5 \%$ in the event of a $1 \%$ depreciation. This may have reflected the considerable uncertainties of Period 1, when the new 'market determined exchange rate' regime had just begun, reserves were small, and there were fears of a depreciation.

In Period 2, the mean exposure shifted dramatically to -0.2. With greater currency flexibility, firms were unsure about how the currency would move, and the overall average exposure dropped to small values.

In Period 3, there were expectations of an INR appreciation. The mean exposure shifted to -0.835 : firm value stood to gain by $0.835 \%$ in the event of a $1 \%$ appreciation.

Finally, in Period 4, reflecting greater volatility, the mean firm exposure declined to $0.673 \%$.

In order to judge their statistical significance of these descriptive statistics, Table 7 shows results for $\bar{\beta}_{2}$ across the four periods.

In Period 1, while the estimated $\bar{\beta}_{2}$ is 2.6325 , where firms as a whole appear to have set themselves up to profit from a depreciation, the standard error of this estimate was 1.609. It is, then, not possible to reject $H_{0}: \bar{\beta}_{2}=0$.

Similarly, in Period 2, while the estimated $\bar{\beta}_{2}$ was -0.2 , where firms as a whole appear to have set themselves up to profit slightly from an appreciation, the standard error of this estimate was 0.125 and it is not possible to reject $H_{0}: \bar{\beta}_{2}=0$. 
Statistical significance is found in Periods 3 and 4 . In both these periods, firms appear to have set themselves up to profit from an appreciation, with ' $t$ ' statistics of 2.27 and 5.52 respectively. Hence, in Periods 3 and 4, there is evidence of homogeneity of firm exposure, of firms as a whole perceiving a one-way bet that the INR was going to appreciate.

We can reject the null of no-change ${ }^{9}$ of the distribution of $\beta_{2 j}$ across consecutive periods: each time the currency regime changed, the distribution of $\beta_{2 j}$ changed.

In the analysis of $\overline{\left|\beta_{2}\right|}$, there was clear evidence that across all four periods, the change in firm exposure was significant. However, the analysis of $\bar{\beta}_{2}$ suggests that there was significant heterogeneity of expectations on the part of firms in Period 1 and 2. Some firms placed a bet on appreciation while some firms placed a bet on depreciation.

In contrast, when we come to Periods 3 and 4 , the results are qualitatively different. Table 5 shows that the size of exposures in Period 4 dropped to less than half that of Period 3. However, in both these periods, firms appear to have felt there was a one-way bet where INR appreciation was likely, or conversely, that a substantial INR depreciation was not going to take place.

Period 4 is a striking situation, where currency volatility was higher, and $\overline{\left|\beta_{2}\right|}$ dropped sharply. However, a strong homogeneity of views is found; we can confidently reject $H_{0}$ : $\bar{\beta}_{2}=0$. Firms seemed to expect that there is little risk of a large INR depreciation, and perceived a one-way bet that INR appreciation is likely.

\section{Conclusions}

This paper shows that in the Indian setting, implicit guarantees offered by the central bank shape the behaviour of firms. Firms choose to hedge or not hedge their exposures depending on whether exchange rate flexibility is high or low - in each of three transitions of the currency regime, substantial changes in firm exposure took place. In addition, large reserves and sustained reserves accumulation seems to generate homogeneity of views amongst firms encouraging firms to believe that the rupee would not depreciate. These results support the hypothesis that pegged exchange rates and large reserves holdings induce moral hazard and increase financial fragility.

These results pertain to the Indian setting, where financial markets gave firms adequate opportunities to modify their currency exposure. In countries where financial markets are underdeveloped, central banks may peg the currency in response to balance sheet mismatches based on an incomplete markets argument. This paper finds that in the Indian

\footnotetext{
${ }^{9}$ Kolmogorov-Smirnov tests applied to the distribution of $\beta_{2 j}$ across consecutive periods show that the null of identical distributions is rejected with prob values of $3.056 \times 10^{-8}$ for the transition from Period 1 to Period 2; a prob value of $1.1815 \times 10^{-5}$ for the transition from Period 2 to Period 3 and a prob value of 0.0496 for the transition from Period 3 to Period 4 .
} 
setting, markets were complete enough to allow firms to modify their currency exposure, that the implicit government guarantee provided through low currency volatility incentivises firms to carry unhedged exposure.

In this paper, a cross-sectional exploration of firm characteristics, seeking to understand which firms hold bigger currency exposure, has not been undertaken. The pattern of ownership, especially the role played by government ownership and its impact on incentives, could be a factor shaping the decisions of firms. This is left to future research. 


\section{References}

Adler, M. and B. Dumas, "Exposure to Currency Risk: Definition and Measurement," Financial Management 13 (1984), 41-50.

Andrews, D. W. K. and J. C. Monahan, "An Improved Heteroskedasticity and Autocorrelation Consistent Covariance Matrix Estimator," Econometrica 60 (1992), 953-966.

Bai, J. and P. Perron, "Computation and Analysis of Multiple Structural Change Models," Journal of Applied Econometrics 18 (2003), 1-22.

Bodnar, G. M. and M. H. F. Wong, "Estimating Exchange Rate Exposures: Some "Weighty" Issues," Technical Report, NBER, 2000.

Burnside, A., M. Eichenbaum and S. Rebelo, "Hedging and Financial Fragility in Fixed Exchange Rate Regimes," European Economic Review 45 (2001), 1151-1193.

Calvo, G. A. and C. M. Reinhart, "Fear of floating," Quarterly Journal of Economics CXVII (May 2002), 379-408.

Chang, R. and A. Velasco, "Currency mismatches and monetary policy: A tale of two equilibria," Harvard University (2005).

Cowan, K., E. Hansen and L. Herrera, "Currency Mismatches, Balance Sheet Effects and Hedging in Chilean Non-Financial Corporations," Eighth Annual Conference of the Central Bank of Chile,External Vulnerability and Policies for Prevention, Santiago, Chile (2004).

Dahlquist, M. and G. Robertsson, "Exchange rate exposure, risk premia, and firm characteristics," Technical Report, Duke University, Durham, North Carolina, 2001.

Dominguez, K. M. and L. L. Tesar, "Exchange rate exposure," Journal of International Economics 68 (January 2006), 188-218.

Doukas, J. A., P. H. Hall and L. H. Lang, "Exchange Rate Exposure at the Firm and Industry Level," Financial Markets, Institutions and Instruments 12 (2001).

Eichengreen, B. and R. Hausmann, "Exchange Rates and Financial Fragility," NBER Working Papers 7418, National Bureau of Economic Research, Inc, November 1999.

Fischer, S., "Dollarisation," Technical Report, Bank of Israel, 2006.

Ghosh, A., A.-M. Gulde and H. Wolf, "Exchange rate regimes: Classification and consequences," Technical Report, IMF, May 2002.

Ize, A. and E. Yeyati, "Financial Dollarization," Journal of International Economics 59 (2003), $323-347$.

Jorion, P., "The Exchange-Rate Exposure of U.S Multinationals," The Journal of Business 63 (July 1990), 331-345.

Kamil, H., "Does moving to a flexible exchange rate regime reduce currency mismatches in firms' balance sheets?," Technical Report, IMF, November 2006. 
Levy-Yeyati, E. and F. Sturzenegger, "Classifying exchange rate regimes: Deeds vs. words," Technical Report, Universidad Torcuato Di Tella, February 2003.

Luca, A. and H. Zhang, "Balance sheets and exchange rate regimes:Estimating the interrelationships," Technical Report, Unpublished paper, Drexel University, 2006.

Martinez, L. and A. Werner, "The Exchange Rate Regime and the Currency Composition of Corporate Debt: The Mexican Experience," Journal of Development Economics 69 (2002), $315-34$.

Parsley, D. C. and H. A. Popper, "Exchange rate pegs and foreign exchange exposure in East and South East Asia," Journal of International Money and Finance 25 (October 2006), 992-1009.

Patnaik, I., "India's experience with a pegged exchange rate," in S. Bery, B. Bosworth and A. Panagariya, eds., The India Policy Forum 2004 (Brookings Institution Press and NCAER, 2005), 189-226.

Patnaik, I., "India's currency regime and its consequences," Economic and Political Weekly (March 2007).

Reinhart, C. M. and K. S. Rogoff, "The Modern History of Exchange Rate Arrangements: A Reinterpretation," The Quarterly Journal of Economics 119 (February 2004), 1-48.

Schneider, M. and A. Tornell, "Balance Sheet Effects, Bailout Guarantees and Financial Crises," Review of Economic Studies 71 (2004), 883-913.

Shah, A. and I. Patnaik, "India's experience with capital flows: The elusive quest for a sustainable current account deficit," in S. Edwards, ed., Capital controls and capital flows in emerging economies: Policies, practices and consequenceschapter 13 (The University of Chicago Press, 2007), 609-643.

Shah, A. and S. Thomas, "Market microstructure considerations in index construction," in CBOT Research Symposium Proceedings (Chicago Board of Trade, 1998), 173-193.

Thomas, S., "How the financial sector in India was reformed," in S. Narayan, ed., Documenting reforms: Case studies from India (New Delhi: Macmillan India, 2006), 171-210.

Zeileis, A., F. Leisch, C. Kleiber and K. Hornik, "Monitoring Structural Change in Dynamic Econometric Models," Journal of Applied Econometrics 20 (2005), 99-121. 